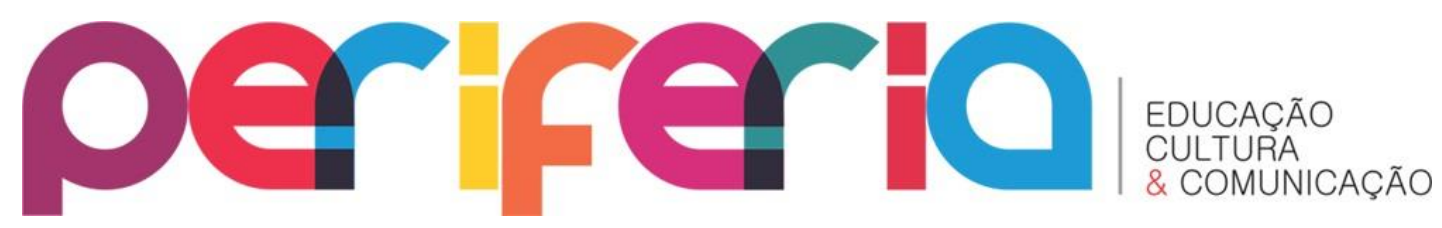

\title{
PENSANDO E DISCUTINO AFRODIÁSPORAS E TERREIROS: CRIANÇAS, EDUCAÇÃO, RACISMO E IMAGEM
}

\section{Cristiano Sant'Anna ${ }^{1}$ Stela Caputo $^{2}$}

\section{Marielle: presente! \\ Hoje e sempre! \\ Anderson: presente! \\ Hoje e sempre!}

Escrevemos esse editorial em meio a muitas dores. No dia 14 de março de 2018, a vereadora carioca Marielle Franco foi executada, com quatro tiros na cabeça. Mulher, negra, oriunda da favela, militante profunda e corajosamente contrária à violência policial. O covarde assassinato teve intensa repercussão. Manifestações de rua espalharam-se pelo Brasil e pelo mundo reunindo milhares de pessoas. Na sociedade do compartilhamento (SANT’ANNA, 2017), onde imagens são produzidas, consumidas e compartilhadas a todo tempo, também foram intensas as mobilizações nas redes sociais que multiplicaram o choque, a indignação e a comoção com tamanha brutalidade. No mesmo mês, cinco jovens foram chacinados em Maricá, região metropolitana do Rio. A Organizações das Nações Unidas informa que, no Brasil, sete em cada dez pessoas assassinadas são negras. Na faixa etária de 15 a 29 anos, são cinco vidas perdidas para a violência a cada duas horas. Também segundo a ONU, de 2005 a 2015, enquanto a taxa de homicídios por 100 mil habitantes teve queda de $12 \%$ para os não-negros, entre os negros houve aumento de $18,2 \%$. A entidade alerta que a letalidade das pessoas negras vem aumentando e isto exige políticas com foco na superação das desigualdades raciais.

No ano em que a abolição da escravatura no Brasil completa 130 anos, todos esses dados não são novidades para a população negra que sente na carne o racismo e o

\footnotetext{
${ }^{1}$ Doutor em Educação (PROPED/UERJ), Membro Pesquisador dos Grupos Kékeré e Currículo, Narrativas Audiovisuais e Diferença - CUNADI (CNPQ), Professor Seeduc/RJ

2 Doutora em Educação (PUC/RJ), Professora da Faculdade de Educação da UERJ e do PROPED, Coordenadora do Grupo de Pesquisa Kékeré (CNPQ)
} 


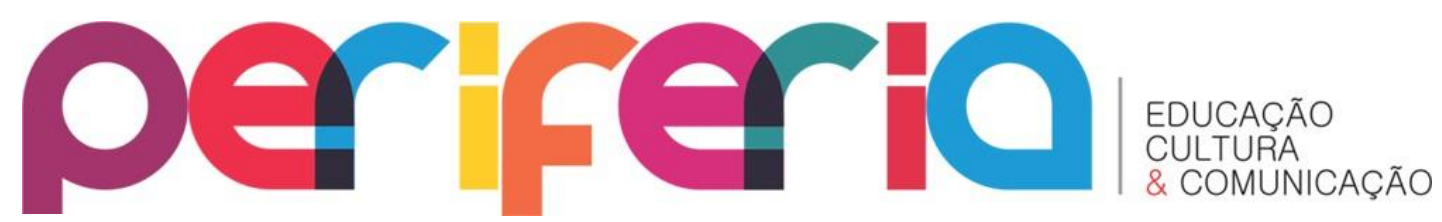

extermínio nesse país com o maior quantitativo de negros escravizados e último do mundo a abolir a escravidão. Ontem senzala e chibata, hoje favela e bala. Os versos da música da música do Rappa: "todo camburão tem um pouco de navio negreiro", traduzem bem o contexto desse racismo estrutural e estruturante da sociedade brasileira.

Essa é a história em que estamos mergulhados ao escrever esse editorial. Uma parlamentar executada, jovens negros mortos cotidianamente e um golpe em curso no Brasil, cujo último ato (por enquanto) foi prender o ex-presidente Lula. Difícil é então organizar ideias e sentimentos, principalmente nós, da UERJ, uma universidade violentada pelo governo do Rio de Janeiro com total apoio do governo Temer, usurpador e golpista.

Quando pensamos o dossiê: “Afrodiásporas e terreiros: crianças, educação, racismo e imagem", pensamos em acolher artigos que enfatizassem qualquer um desses temas em separado ou em conjunto. Sobre especificamente crianças de terreiros, seus aprendizados nas casas de santo, seus conhecimentos, suas relações na hierarquia dos candomblés existe muito pouca pesquisa.

Pritchard (2005), em seus estudos sobre os $\mathrm{Azande}^{3}$, ao falar das dificuldades de aproximação com campos de pesquisas com pessoas desconhecidas, recomenda a aproximação inicial através das crianças do grupo. "Entre os Azande, comecei por pedir aos meninos que me ensinassem jogos, e entre os Nuer, a ir pescar toda manhã com os rapazes. Descobri que, quando as crianças me aceitavam, então os adultos também me aceitariam". (PRITCHARD, 2005, p.254).

A afirmação do antropólogo nos evidencia a secundarização das crianças, mesmo as que a antropologia considerava como "informantes". Para Pritchard (2005), as crianças do grupo pesquisado tinham valor de pontes utilitárias que serviriam apenas para facilitar sua chegada a quem "realmente sabia", a quem, na sua concepção, realmente traria informações importantes sobre o campo. Acreditamos que as pesquisas com crianças de candomblé precisam inverter essa lógica utilitarista e adultocêntrica. Mas isso é apenas uma, das tantas questões a serem enfrentadas nas pesquisas com

${ }^{3}$ A pátria tradicional dos Azande está atualmente cortada pelas fronteiras de três Estados africanos modernos: a República do Sudão, o Zaire (atual República Democrática do Congo) e a República Centro-Africana. 


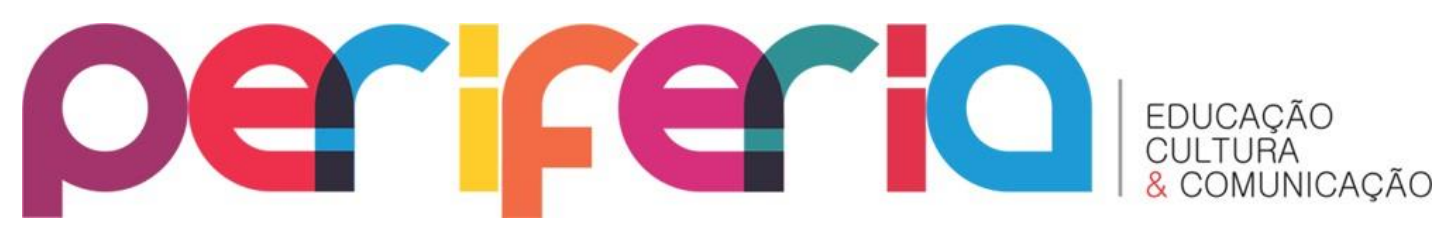

crianças de candomblé. Uma outra questão é realmente fazer pesquisas com crianças e não sobre as crianças dedicamdo-lhes tempo, muito tempo, tempo mesmo. Ouvir, observar, conversar são necessidades vitais para que as crianças tenham, de fato, o protagonismo dos sujeitos dinâmicos que são hoje (CAPUTO, 2018) e não o "ainda não", os seres em "vias de o ser", como critica Sarmento (2008).

A respeito disso temos sido inspirados por alguns provérbios africanos: $O$ primeiro deles diz o seguinte: "Ninguém experimenta a profundidade do rio com os dois pés". As pesquisas com crianças de terreiros em terreiros foram iniciadas pelos estudos de Caputo (1992, 2005, 2006, 2012, 2018). O estudo é recente, mas o tema profundo, imenso. Um assunto tão gigantesco e desafiador sugere cautela. É preciso entrar com um pé, depois o outro. Entrar enfiando os dois e já sair tentando nadar de braçada não dará certo. Tempo.

Outro provérbio é do sábio Tierno Bokar e diz assim: "Se queres saber quem eu sou, se queres que eu te ensine o que sei, deixa um pouco de ser o que tu és e esquece o que sabes". Ou seja: há que se levar sim estudos de outras áreas: educação, sociologia, antropologia, etc, mas com cautela. As questões despertadas pelas crianças de candomblé são singulares demais para caberem, de qualquer modo, na roupa de áreas de estudos que jamais pensaram nelas. Elas não vão entrar ali, na roupa que estava guardada faz tempo no armário e que, de repente, é sacada para vestir esse novo tema. Isso nos lembra a expressão usada, há muitos anos, por um senhor nigeriano que estava ao nosso lado, em uma palestra na UERJ. O tema era outro, mas a crítica que ele fez vai no sentido que tentamos deixar aqui: "Se você tem um corpo grande, não use um bubu ${ }^{4}$ pequeno demais". O conselho serve para as tentativas quase sempre inadequadas de tentar vestir o que vemos com velhos trajes já pequenos demais. O corpo novo não terá obrigação de entrar na roupa velha.

As crianças de candomblé foram desprezadas mesmo pelos estudiosos clássicos do candomblé, mas elas são crianças DE candomblé. E aí vem outro gigantesco desafio.

\footnotetext{
${ }^{4}$ Boubou/ Bubu é um dos nomes usados para um robe de mangas largas e esvoaçantes usado na maior parte da África Ocidental, e parte da África do Norte.
} 


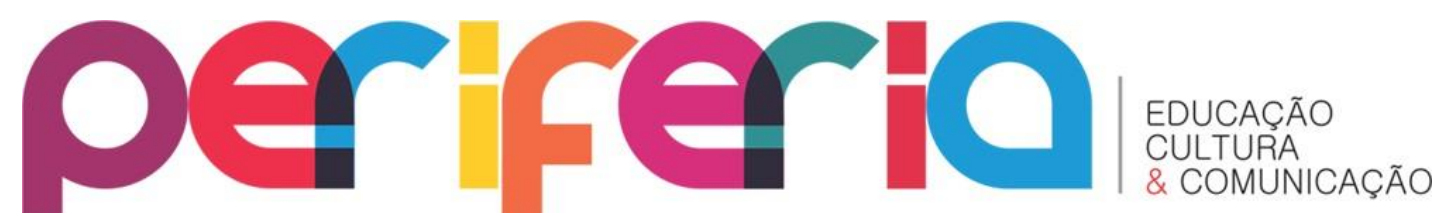

Se um pesquisador é neófito tanto no tema específico das crianças de candomblé e neófito nas pesquisas de candomblé sugerimos um cuidado multiplicado. Rituais, termos, nomes, cargos, tudo e qualquer minúscula coisa precisa ser estudada com extrema dedicação. Não se compreende o candomblé da noite para o dia. E aí, ouvimos com empenho mais um provérbio africano: "Um estranho visitante que pede o caminho não vai se perder". Cuidado, dedicação, ética, humildade de pesquisa são caminhos fundamentais para que o campo das pesquisas com crianças de candomblé se alargue e desestabilize espaços e áreas de conhecimentos.

Os artigos reunidos aqui, apresentam discussões sobre pesquisas que protagonizam as afrodiásporas e suas interrelações com diversos espaçostempos ${ }^{5}$ de discussão, pesquisa e estudo.

$\mathrm{O}$ artigo "A representação do negro na literatura infantil brasileira" de Jessica Oliveira Farias, por exemplo, apresenta uma pesquisa, que teve como foco a análise da trajetória da representação das personagens negras na produção literária infantil brasileira, do início do século XX até os primeiros anos do século XXI. Em seu trabalho, a autora buscou obras que valorizassem a identidade afro-brasileira para um trabalho com africanidades e relações sociais nas séries iniciais do ensino fundamental, percebendo a literatura, como reflexo da sociedade, que excluiu ou tratou os afrodescendentes de forma diferenciada ao longo de muitos anos na história do Brasil. Os resultados apresentados demonstram como a representação do negro na Literatura infantil passou por fases como omissão; estereotipação; e deturpação da imagem, do caráter e inteligência. Além disso, foram analisadas algumas opiniões acerca da censura nos acervos literários escolares e citados exemplos de textos que podem ser explorados em um trabalho pedagógico preocupado com as relações étnicas no ambiente escolar.

Já o texto de Jonathan Machado Domingues, "Brincar na infância plural: da educação jesuíta ao estudo da ludicidade" traz a contextualização do universo plural da infância, o brincar e a questão educacional e curricular. Nesse contexto, brincar se

\footnotetext{
${ }^{5}$ Utilizamos essa grafia, nesses termos, pela necessidade na pesquisa nos/dos/com os cotidianos de mostrar os limites herdados do modo de criar conhecimento próprio da ciência moderna, com as dicotomias necessárias à produção do conhecimento científico.
} 


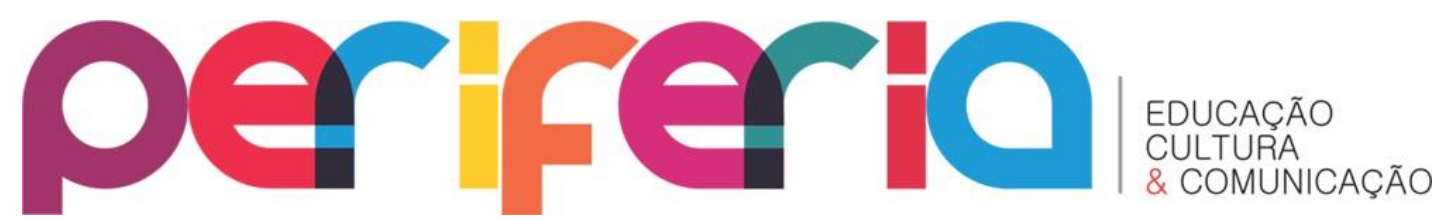

apresenta como uma ação praticada e realizada por todos os componentes sociais, afirmando que cada grupo social, referindo-se o meio que se encontra, tem/pratica brincadeira exclusiva e/ou a mesma brincadeira em várias localidades. Como exemplificação os nomes titulados ou as regras destas são diferenciados de lugar para lugar, em função da cultura local, cultura lúdica. Igualmente, como objetivo secundário, foi tratada a questão educacional jesuítica no período Colonial no Brasil. Também foram abordadas as questões históricas da infância juntamente com a formação do corpo docente ligado à finalidade da escola tanto para a classe mais rica quanto para a mais pobre, com a observação de que a palavra infância e família, tal como sabemos hoje, são sentimentos criados pela burguesia. O autor conclui que o brincar vai além de um simples entretenimento. Trata-se de um estágio de preparação da criança para a vida adulta com a utilização da construção do simbólico, relacionado ao brinquedo, como ferramenta.

"Oxumaré também mora aqui!": o olhar de crianças de terreiro sobre a festa de São Bartolomeu" é o título do artigo de Hellen Mabel Santana Silva, Marise de Santana e Edson Dias Ferreira que trazem considerações a partir dos desenhos de crianças de terreiro sobre o legado africano existente na festa de São Bartolomeu, que acontece na cidade de Maragojipe-Ba, situada no Recôncavo Baiano. O artigo centra-se em investigar como as crianças maragojipanas com identidade afro-brasileira desenham um dos territórios culturais do festejo a São Bartolomeu, santo católico sincreticamente relacionado ao orixá Oxumaré. Ou autores compreedem que a cidade de Maragojipe possui um legado ancestral africano entranhado em sua constituição histórica e cultural. Assim, para além dos elementos da cultura católica, reverberados pela memória oficial, o espaço maragojipano apresenta também símbolos e mitos originários dos povos africanos e afro-brasileiros que se territorializam através das identidades dos sujeitos, por exemplo, no momento de festejar o santo padroeiro da cidade. Na produção imagética das crianças, fez-se possível para os autores, conhecer o universo cosmogônico dos seus territórios étnicos desde a preparação do festejo, até o momento em que os corpos, cores, cheiros e sabores celebram nas ruas da cidade São Bartolomeu e Oxumaré. A pesquisa é um estudo etnográfico, com esteios básicos na prática da 


\section{periferio}

observação e análise das dinâmicas interativas e comunicativas dos sujeitos em seus espaços. O desenvolvimento de oficinas gerou a produção imagética das crianças, possibilitando conhecer o território cultural da festa de São Bartolomeu através do olhar de quem experiencia o festejo a partir do seu próprio território e das relações estendidas com o universo cultural africano e afro-brasileiro.

Resultado de sua tese de doutorado em Educação intitulada "Exu e a Pedagogia das Encruzilhadas", o autor Luiz Rufino Rodrigues Junior apresenta o artigo: "Pedagogia das Encruzilhadas", que tem como proposta desenvolver a crítica e sugerir outros caminhos nas abordagens sobre racismo, colonialismo e educação. Com seu texto, Rufino pretende invocar e encarnar as potências de Exu, divindade iorubana transladada na diáspora, para propor uma Pedagogia das Encruzilhadas. O autor parte da defesa da não redenção ao colonialismo, problematizando a continuidade de seus efeitos na formação de um mundo múltiplo e inacabado, lido, aqui, a partir da disponibilidade conceitual assente na encruzilhada de Exu - que emerge, assim, como símbolo de um projeto político/poético/educativo outro. A pedagogia encarnada pelas potências do orixá, diz ele, tece um balaio de múltiplos conceitos que confrontam a arrogância e a primazia dos modos edificados pela lógica colonial. Dessa forma, mais que confrontar os limites da razão dominante, a proposta do pesquisador se lança e aponta outros caminhos: a partir de invenções paridas nas fronteiras e nos vazios deixados, são sabedorias reconstrutoras dos seres que, na invenção do Novo Mundo, foram submetidos à política de subordinação, encarceramento e morte da raça/racismo. A educação, nesse sentido, é apresentada como caminhos enquanto possibilidades de reinvenção de seres, uma resposta responsável e comprometida com a justiça cognitiva/social e com a vida em sua diversidade e imanência.

Marcos Eduardo Leandro e Lucio Bernard Sanfilippo trazem o artigo "Deus e o diabo na prateleira do mercado: reflexões e narrativas de um racismo religioso vigente" que propõe discutir e denunciar a crescente onda de violência que vem se abatendo sobre terreiros de candomblé por todo o Brasil, mais ainda em Nova Iguaçu, cidade da Baixada Fluminense, na periferia do Rio de Janeiro. Nesse contexto, os autores explicam que os autodenominados traficantes de Cristo, cientes da impunidade, 


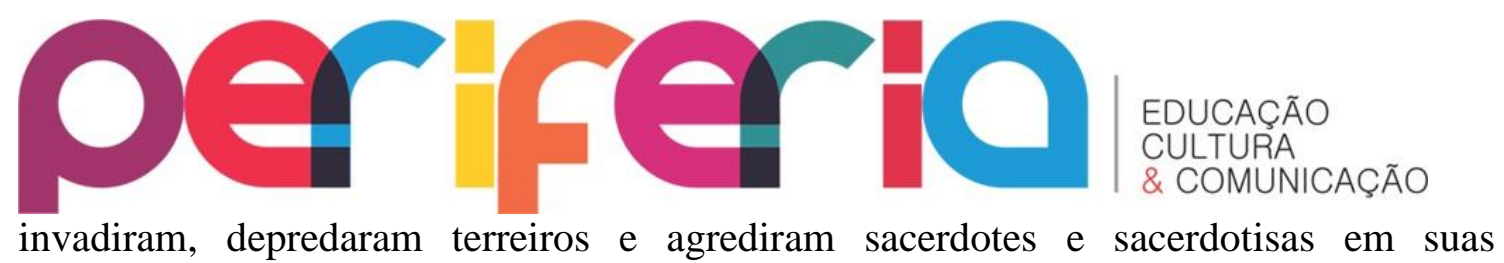
comunidades tradicionais de matrizes africanas. Analisando fatores históricos - pois que esses fatos sempre estiveram presentes nos cotidianos dos cultos afro-brasileiros, a trajetória do racismo religioso e o crescimento das igrejas neopentecostais em todo país, os autores refletem sobre essa violência e suas implicações nos contextos políticos e culturais da atual conjuntura, demonstrando que de acordo com as narrativas que levam à demonização das religiões de matriz africana, presenciamos um projeto de poder político-institucional que viola direitos humanos e constitucionais, além de estarem alinhados a setores conservadores e obscurantistas da sociedade.

"Identidade religiosa do médium surdo no terreiro de Mina Jeje Nagô Huevy em Belém (Pará)" é o título do artigo de Sergio Mauricio de Oliveira Junior, Silvio Santiago-Vieira e Jakson Santos Ribeiro que apresenta uma pesquisa que teve como objetivo compreender a representação simbólica de Ogum, Iemanjá e Xangô na construção da identidade religiosa do médium surdo na Casa Grande de Mina Jeje Nagô de Toy Lissá e Abê Manjá Huevy, pertencente ao Tambor de Mina. Para o desenvolvimento do trabalho o autor empreendeu etnografia. Observou o pesquisador que a identidade religiosa do indivíduo estudado é constituída de inúmeros fatores, incluindo a representação simbólica desses Orixás, tecida como um fator principal na constituição identitária do médium surdo.

Caroline Delfino dos Santos apresenta o artigo "Diálogos entre afrodiáspora e educação: por um currículo a favor das culturas negras". A autora traz a discussão de que a diáspora africana, ou afrodiáspora, foi e segue como resultado de um processo de mercantilização ora no período de colonização, ora na contemporaneidade. Os mais variados deslocamentos e com eles contínuos processos de desterritorialidade implicam um olhar em torno das práticas de aculturamento, silenciamento e apagamento cultural dos povos negros. Assim, o presente artigo justifica-se a partir da constatação da chegada de crianças em situação de deslocamentos às escolas públicas municipais de Duque de Caxias/RJ, concomitante à demanda apresentada pela Lei 10.639/03 que prevê o estudo da História da África e dos Africanos no currículo escolar. O cenário escolar revela-se como um reflexo da sociedade, na medida em que tende a projetar nos 


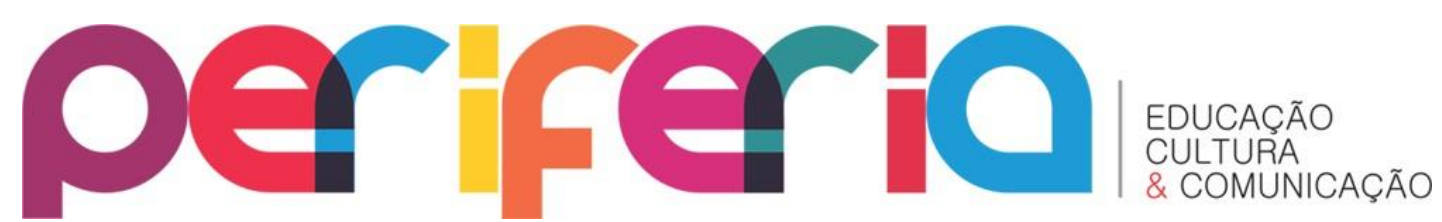

alunos um determinado padrão estético e comportamental a partir de uma dada cultura: a cultura do masculino, do hétero, do cristão, do branco, do europeu. Embora configurese como um espaço demograficamente diversificado, quase sempre os valores impostos amparam-se numa perspectiva monocultural. Dessa forma, elenca-se como objetivo chamar a atenção para a necessidade de se pensar o currículo a partir de uma perspectiva a favor da cultura africana com contribuições advindas das trajetórias das crianças em contexto de diáspora. O método empregado apoiou-se nas contribuições da observação participante em razão da interação entre a pesquisadora e os sujeitos envolvidos, utilizando-se ainda de entrevistas com alunos do $5^{\circ}$ ano de escolaridade de uma dada escola pública do município de Duque de Caxias/RJ.

"O mundo se despedaça na sala de aula: ensino de história e literatura" é o título do artigo de Lázaro de Souza Barbosa e Pedro Alberto Cruz de Souza Gomes que tem como objetivo apresentar o diálogo entre história e literatura como possibilidade viável no ensino de história. Com a utilização do livro "O mundo se despedaça", de Chinua Achebe, abre-se caminhos para o entendimento da história da África e dos africanos como preconizam as leis 10. 639/2003 e 11. 645/2008 (que aliás, completa 15 anos justamente esse ano), e para a contraposição às históricas narrativas que negativizaram, ou negaram as experiências subjetivas, conceituais, teológicas e culturais de africanos no tempo, no espaço e na diáspora. O trabalho apresenta considerações sobre as relações entre história e literatura, contextualiza historicamente a obra do escritor nigeriano Chinua Achebe, analisa representação literária que o escritor faz sobre a religiosidade do povo Ibo e, por fim, pensa uma perspectiva de insurgência epistêmica com a utilização do livro "O mundo se despedaça" como recurso didático para o ensino de história. Texto muito bem-vindo também porque pouco se conhece Achebe, escritor que precisamos espalhar po nossas bandas.

Em "Outros Negros", o autor Ademir Barros Santos, apresenta artigo em contraponto à história conhecida hegemonicamente. Traz outras posturas das negritudes transpostas compulsoriamente para o Novo Mundo, já que os meios oficiais, ainda hoje, enfatizam a dominação pacífica do europeu sobre o africano que, no extremo, ainda é visto, mesmo, como conivente com o processo. O autor afirma como necessária a 


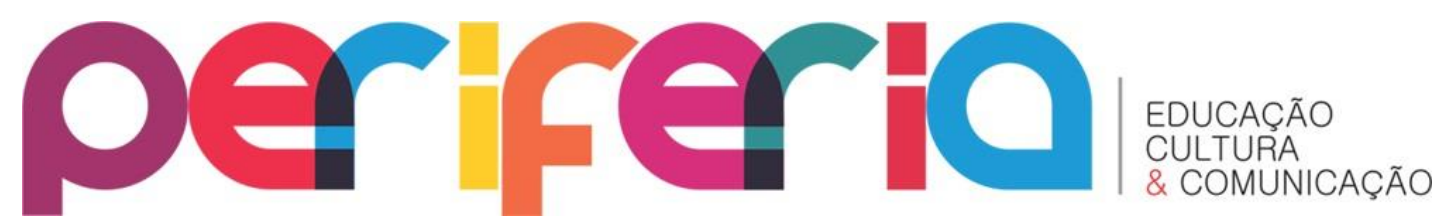

constante vigilância sobre o contínuo e persistente apagamento da ação dos movimentos culturais e sociais que os próprios negros produziram, instrumentalizando a cultura nacional à procura de caminhos para própria libertação. É com este intuito que esta análise se dispõe a discorrer sobre a evolução dos processos de enfrentamento à dominação europeia ocorrida no Brasil, com ênfase na ininterrupta resistência cultural que, ao final, permitiu a sobrevivência dos saberes de matriz africana em suas diversas formas e nuances, inclusive como instrumentalizadora da sociedade nacional, o que se torna evidente ainda nos dias atuais.

“O gingado que vem da África: a capoeira na construção da identidade negra no Brasil" é o título do artigo de Maressa Carolina Lopes Faria e Nayara Cristina Carneiro Araújo que nos traz uma pesquisa que analisa a influência da cultura africana na formação da identidade brasileira especificamente a partir da capoeira, discutindo identidade negra na capoeira. A questão principal é identificar se a valorização da influência africana a partir da capoeira é fator positivo no combate ao racismo, tendo em vista a percepção de indivíduos capoeiras. Para tanto, discute-se identidade desstacando a importância da cultura para a formação da identidade. Há ainda a análise dos primeiros registros iconográficos, o nascimento de uma nova tradição da capoeira (1930-1940) e o processo de folclorização e esportização (1950-1970), além do parecer que registrou a capoeira como patrimônio cultural do Brasil, utilizando-se de crítica bibliográfica como metodologia para a análise histórica. $\mathrm{O}$ artigo também destaca como a capoeira é fundamental na valorização do negro e de sua história em nosso país, identificando as manifestações culturais negras, principalmente no que se trata da capoeira, incorporadas como contribuição para a cultura brasileira a partir do século $\mathrm{XX}$.

Jeusamir Alves Silva traz o artigo "Da história negada a luta por uma visibilidade igualada", que através do Candomblé Banto, procura identificar, catalogar e inventariar o patrimônio cultural afro banto brasileiro de forma possível a estabelecer o diálogo voltado para a difusão e a preservação dos valores identitários presentes nas referências patrimoniais do território brasileiro, visando a inclusão da sua história e cultura e religiosidade nas grades curriculares do ensino brasileiro. $\mathrm{O}$ autor, 


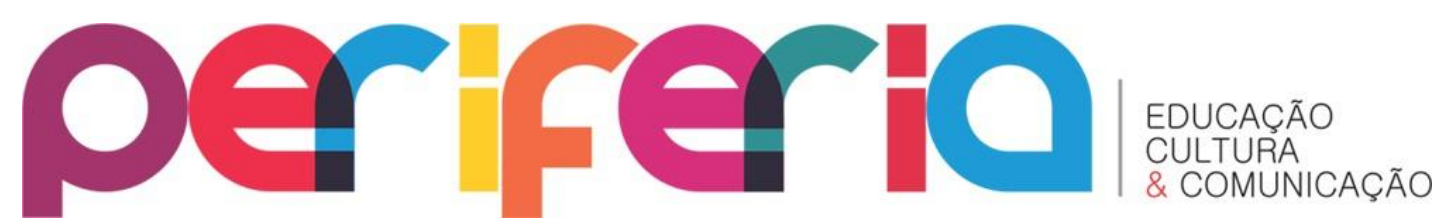

considerando que o território brasileiro caracteriza-se pelos altos índices de afrodescendentes na formação de sua população em geral, acreditam que um projeto de pesquisa voltado para a preservação do patrimônio e a cultura afro banta brasileira também representa a possibilidade de proporcionar a formação de, a capacitação e a atualização de professores da rede pública de ensino, como implementação da lei 10.639/2003/PR. O texto apresenta como objeto de estudo, terreiros bantos de diferentes pontos do Brasil. A justificativa se fez porque, apesar dos bantos terem sido os primeiros escravos aqui introduzidos, e espalhados por todo território brasileiro, (do século XVI ao XIX), praticamente nada se sabe-se sobre o seu papel na formação do Brasil e na construção da nossa língua. Utilizou-se a pesquisa de campo baseada em visitas a terreiros, bem como, entrevistas com sacerdotes: Tata Katuwanjesi (Walmir Damasceno), presidente do ILABANTU - Instituto Latino Americano de Tradições Afro-Bantu, em Itapecerica da Serra-SP. Tata Kassulupongo (Moisés Queirós), dirigente da Casa do Benguê ria Lembaranganga, em Extremóz - RN, Mam'etu Nangakovi (Risoleta de Oliveira), do Terreiro de Matamba, emde São João de Meriti RJ , entre outros. Confirmou-se então, a importância desse povo, na construção da nossa língua e na formação da nação brasileira. Com os resultados obtidos e o interesse acadêmico, o autor espera alcançar em breve, a inclusão e visibilidade desejadas, bem como ter, também, registrado nos anais da história o Candomblé de Tradição Banto, como religião afro-brasileira.

Alisson Araujo de Almeida apresenta no seu artigo "Candomblé e as duas diásporas do povo negro: o país mítico e a invasão da intolerância" como um desdobramento da revisão bibliográfica realizada para a pesquisa de doutorado Les jeux de Masque au sein du Candomblé, Dramaturgia de la Fête dans l'Espace. Neste artigo, o olhar antropológico ofereceu uma atenção maior ao processo de reconstrução da alteridade negra na diáspora brasileira. Para o autor, o Candomblé passou a ser compreendido como uma unidade nas diferenças, onde o acesso aos ancestrais permite a expressão de alteridades. Contudo, as reflexões lançadas neste artigo pretendem verificar as diversas visões que têm gerado o que considera uma evasão no Candomblé e um aumento da intolerância. Para o autor, este artigo é o embrião de uma futura 


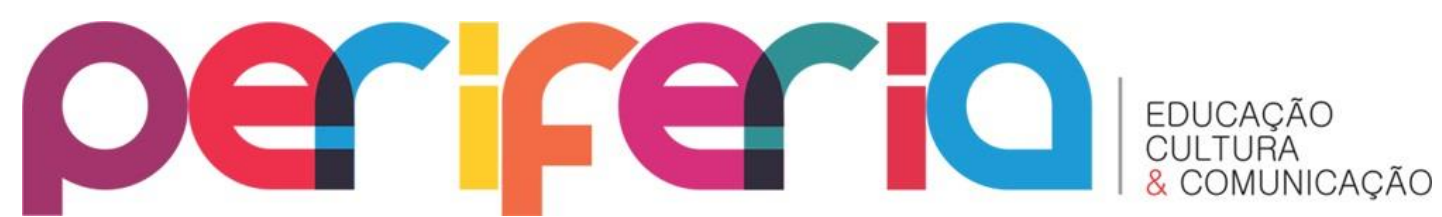

pesquisa que irá investigar a potência criativa do Candomblé assim como suas contradições.

Esse número da Periferia também traz os artigos de fluxo contínuo: "Conhecimento, conhecimento escolar e discurso pedagógico" dos autores António Fernando Zucula e Carlos Augusto Aguilar Júnior, "Escolas multisseriadas no contexto da Amazônia” dos autores José Valderi Farias de Souza e Rafael Marques Gonçalves, "Redes de saberes: pensamento interdisciplinar" de Marcus Alexandre de Pádua Cavalcanti, "Cultura afro brasileira na Baixada fluminense: pesquisa e ensino" da autora Eliana Laurentino.

E, por fim, apresentamos as resenhas: "Salve São Jorge/Ogum: O padroeiro do carioca" de Guilherme Pereira Stribel e "Somos usuários de sistemas computacionais ou somos usados por eles?” de Felipe da Silva Ponte de Carvalho

Pretendemos que a leitura de nossa revista possa abrir mais e mais caminhos para enfrentarmos o racismo com suas várias faces, incluindo a religiosa. Passados quase 500 anos desde o início do tráfico negreiro o racismo se reinventa. Justamente por isso, precisamos também nós, reinventarmos juntos e juntas nossas lutas cotidianas antirracistas. A universidade só tem sentido se conseguir somar nessa luta.

\section{Referências}

CAPUTO, Stela Guedes. Educação nos terreiros e como a escola se relaciona com crianças de candomblé. Rio de Janeiro: Ed. Pallas, 2012.

SANT'ANNA, Cristiano. \#DIFERENÇA: pensando com imagens dentrofora da escola. Tese de doutorado, Proped/UERJ, 2017 www.proped.pro.br 